\title{
Synthesis and biological evaluation of novel dibenzofluorene derivatives as anticancer agents
}

\author{
BIMAL K. BANIK $^{1}$, CHHANDA MUKHOPADHYAY ${ }^{2}$ and FREDERICK F. BECKER ${ }^{2}$ \\ ${ }^{1}$ Department of Chemistry, The University of Texas-Pan American, Edinburg, TX 78539; ${ }^{2}$ Department of Molecular \\ Pathology, Unit 951, The University of Texas M.D. Anderson Cancer Center, Houston, TX 77504, USA
}

Received August 7, 2009; Accepted October 23, 2009

DOI: $10.3892 /$ ol_00000055

\begin{abstract}
The novel synthesis of dibenzofluorene has been achieved by a cyclodehydration method. Several derivatives have also been prepared using this hydrocarbon. These compounds have been tested against a number of cancer cell lines in vitro, and useful selectivity has been observed.

\section{Introduction}

The synthesis of polycyclic aromatic rings by various methodologies has been extensively documented (1). The carcinogenic properties of these compounds have been explained by advancing different mechanisms (2). The use of polycyclic aromatic compounds and their derivatives as anticancer agents has been explored (3). The antitumor activity of these compounds has been proposed to depend on intercalation with or covalent binding to DNA (4). Many other sites of interaction such as the cell membrane have been identified. We determined that suitably substituted chrysene derivatives act on the cancer cell through interactions with the membrane (5). Although using potentially mutagenic compounds to derive antitumor agents may appear to be a questionable approach, a large body of information supports this concept. Many reports have claimed that alteration of the structure of polycyclic aromatic hydrocarbons can mitigate their deleterious effects, emphasizing their interaction with specific cell organelles to evoke specific cytotoxic reactions. As a result, many of the antitumor agents that are in current clinical use are derived from compounds such as carbazoles, anthracenes and related structures (6).
\end{abstract}

Correspondence to: Dr Bimal K. Banik, Department of Chemistry, The University of Texas-Pan American, 1201 West University Drive, Edinburg, TX 78539, USA

E-mail: banik@panam.edu

Key words: dibenzofluorene, synthesis, biological evaluation, anticancer agent

\section{Materials and methods}

The materials and methods used included: dibenzofluorene, methylmagnesiumiodide, hydroiodic acid, tetrahydrofuran, nitric acid, sulfuric acid, hydrazine, palladium-carbon, ethanol, piperidine, $\mathrm{N}$-methylpiperazine, isobutylchloroformate, triethylamine, diborane, the MTT assay and several cancer cell lines.

All reactions described in this study were carried out under a well-ventilated hood. Some of the compounds described here are potential carcinogens.

\section{Results}

We examined the synthesis and the antitumor activities of structurally complex, angular dibenzofluorene [a,g] polycyclic systems with a very reactive methyl substituted group. The structure-activity relationships of several new diamides and diamines $(8,9)$ are also reported.

We prepared pentacyclic dibenzo[a,g]fluorene (3) in $30 \%$ yield by following the method reported by Harvey et al (7). Hydrocarbon 3 can be prepared via alkylation of the enamine 1 with bromide 2 and cyclodehydration-aromatization of the ketone (scheme 1).

Functionalization of aromatic derivatives by an electrophilic reaction is routine organic chemistry. The orientation of the electrophile in monocyclic or bicyclic derivatives is predictable. However, a substitution reaction in a polycyclic aromatic system is extremely difficult, and for a polycyclic non-alternate hydrocarbon it is poorly predictable. The electrophilic substitution reaction in the polycyclic aromatic system has been poorly described (8). We planned to link a 4-carbon side chain with a heterocyclic base at the end to the aromatic ring through nitrogen. Therefore, we aimed to prepare amino dibenzofluorene 6 for the subsequent derivatization. Towards this goal, we reacted the ketone 4 with nitric acid in acetic acid under different conditions but failed to produce the desired nitro derivative. However, the hydrocarbon 3 produced a single nitro compound with nitric acid-sulfuric acid at $0-5^{\circ} \mathrm{C}$ in an $80 \%$ yield. Reduction of the nitro compound to the amino compound 6 was carried out. Samarium can be used for this reduction (9). Our next task was to prepare the side chains and to couple them to the amine 6 . The amine 6 was then condensed with the 


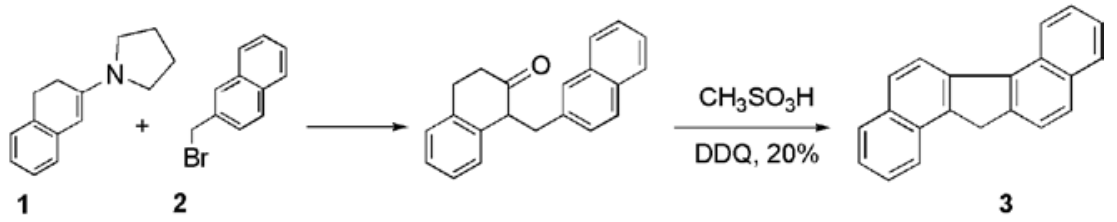

Figure 1. Scheme 1.

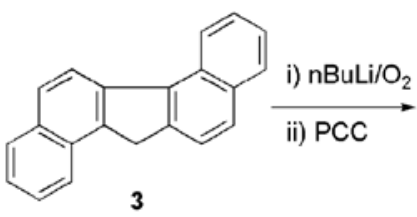

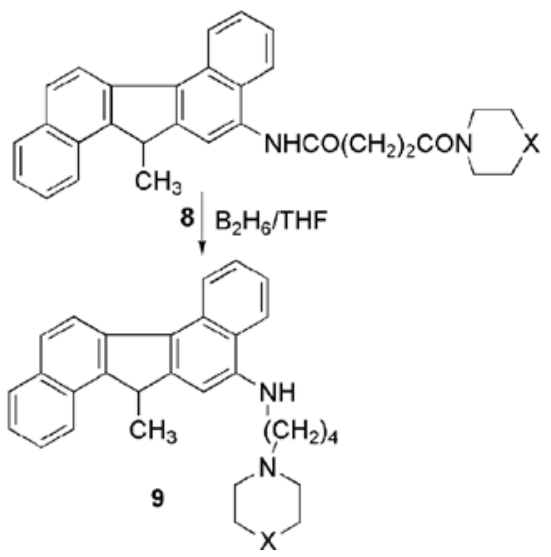<smiles>O=C1c2ccc3ccccc3c2-c2cccc3cccc1c23</smiles>

4<smiles>CC1c2ccc3ccccc3c2-c2ccc3ccccc3c21</smiles>

5 i) $\mathrm{HNO}_{3} / \mathrm{H}_{2} \mathrm{SO}_{4}$ ii) $\mathrm{NH}_{2} \mathrm{NH}_{2} / \mathrm{Pd}-\mathrm{C} / \mathrm{EtOH}$

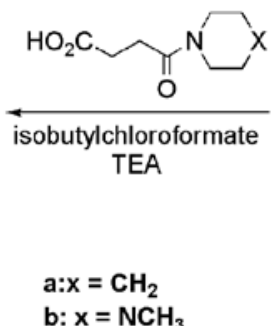<smiles>CC1c2cc(N)c3ccccc3c2-c2ccc3ccccc3c21</smiles>

6

Figure 2. Scheme 2.

Table I. $\mathrm{IC}_{50}(\mu \mathrm{M})$ of compounds 8 and 9 using the MTT assay (a 72-h continuous exposure).

\begin{tabular}{lccccc}
\hline Cell Line & Cisplatin & $8 \mathrm{a}$ & $8 \mathrm{~b}$ & $9 \mathrm{a}$ & $9 \mathrm{~b}$ \\
\hline B16 & 7.33 & $>20$ & 4.30 & 4.05 & 1.65 \\
BRO & 5.66 & $>20$ & 3.88 & 4.38 & 3.65 \\
HL-60 & 1.66 & $>20$ & 3.40 & 3.90 & 3.95 \\
MCF-7 & 15.99 & $>20$ & 4.35 & 4.85 & 4.36 \\
OVCAR 3 & 3.99 & $>20$ & 4.19 & 3.00 & 1.85 \\
P388/0 & - & $>20$ & 4.35 & 4.51 & 4.38 \\
PC 3 & 1.66 & $>20$ & 3.98 & 4.14 & 3.49 \\
HT-29 & 15.99 & $>20$ & 3.80 & 4.14 & 3.20 \\
\hline
\end{tabular}

side chain acid by a mixed anhydride method. Many other condensing agents, such as DCC and HOBt, failed to yield the amides 8 (scheme 2). The desired diamides $8 \mathrm{a}$ and $8 \mathrm{~b}$ were isolated by column chromatography. Reduction of the amide functionality to the amino group by lithium aluminum hydride is a standard chemical transformation. Therefore, in order to produce the diamino compounds, reduction of 8 was carried out by this reagent under a variety of conditions. However, neither of the desired diamino compounds 9a or
$9 \mathrm{~b}$ could be isolated from the complex reaction mixtures by this method. After many experiments, diborane was found to be the reagent of choice for this reaction, and it resulted in a good yield of the amino compound 9. These derivatives were tested against a number of tumor cell lines. As an approach to an operational definition of in vitro antitumor cytotoxicity (activity), we chose to compare the effects of our compounds with those of cisplatin.

\section{Discussion}

The antitumor activity of these newly synthesized dibenzofluorene derivatives 8 and 9 were tested, and a comparison with respect to cisplatin is shown in Table I. The diamide with $\mathrm{N}$-methyl piperazine moiety was more potent than the diamide with piperidine. However, all of the diamines were potent irrespective of the terminal groups. A variation of $0.3-0.8 \mu \mathrm{m}$ was observed.

\section{Acknowledgements}

We gratefully acknowledge the financial support for this research project from NIH/NCI P-2OCA 138022 (B.K.B.) and Cha Family Fund (F.F.B.). We are also thankful to the Pharmacology and Analytical Center Facility of the University of Texas M.D. Anderson Cancer Center. 


\section{References}

1. Harvey RG: Polycyclic Aromatic Hydrocarbons. Wiley-VCH, 1997.

2. Clar E: Polycyclic Hydrocarbons. Academic Press, New York, 1964.

3. Zhang FJ, Cortez C and Harvey RG: New synthetic approaches to polycyclic aromatic hydrocarbons and their carcinogenic oxidized metabolites: derivatives of benzo[s]picene, benzo[rst]pentaphene and dibenzo[b,def]chrysene. J Org Chem 65: 3952-3960, 2000

4. Harvey RG: Chemistry and carcinogenicity. In: Polycyclic Aromatic Hydrocarbons. Chapter 4. Cambridge University Press, 1991.

5. Becker FF and Banik BK: Polycyclic aromatic compounds as anticancer agents: synthesis and biological evaluation of some chrysene derivatives. Bioorg Med Chem 8: 2877-2880, 1998.
6. Palmer BD, Rewcastle GW, Atwell GJ, Baguley BC and Denny WA: Potential antitumor agents. 54. Chromophore requirements for in vivo antitumor activity among the general class of linear tricyclic carboxamides. J Med Chem 31: 707-712, 1988.

7. Harvey RG, Pataki J, Cortez C, DiRaddo P and Yang C: A new general synthesis of polycyclic aromatic compounds based on enamine chemistry. J Org Chem 56: 1210-1217, 1991.

8. Heaney H: In Comprehensive Organic Synthesis. Trost BM (ed). Pergamon Press, Oxford, p753, 1991.

9. Banik BK, Venkatraman MS, Mukhopadhyay C and Becker FF: A facile reduction of aromatic nitro compounds to aromatic amines by samarium and iodine. Tetrahedron Lett 39: 7243-7246, 1998. 